\title{
The Deterioration of Fabrics Exposed on a Roof after Treatment with Fishing-net Preservatives.
}

\author{
By \\ W. R. G. Atkins, Sc.D., F.R.S., \\ Head of the Department of General Physiology at the Plymouth Laboratory.
}

Work on fishing nets showed that the rapid deterioration which they undergo in water is due to bacterial action and may be greatly reduced by the use of appropriate preservatives which hinder bacterial growth. Nets are however exposed to sunlight and to diffuse light also, as well as to the action of rain and wind. It seemed desirable, therefore, to see whether the preservatives found to be of use against bacterial action were also useful in affording protection against the weather and such a degree of moisture as normally occurs in fabrics thus exposed. Instead however of using nets, fabrics were used, as they give rather more uniform results than do nets, each strip tested being made up of many strands. Furthermore, previous experience with fabrics had shown how great their rate of deterioration might be in Egypt, where there is intense sunlight. For example, the linen used on aeroplane wings, when exposed untreated, is reduced to about half its initial tensile strength in fifty days during summer, and the stout fabric of which hangars are made may be reduced to between one-fifth and one-tenth of its tensile strength in ten monthsthis refers to the side facing south, the north side being far less acted on.

It was found that cotton resisted weathering better than linen. Neither cuprammonium treatment (Willesden canvas), treatment with bitumen, rubber proofing nor dyes availed to lessen the rate of deterioration. Proofing with basic aluminium acetate was however definitely better than no treatment.

Conditions in Plymouth are however rather different, the sunlight is less intense, and the fabrics remain wet for longer periods, so that one might expect the deterioration due to bacteria and moulds to be relatively greater than in Egypt, in spite of the lower temperature.

There was another object in view in undertaking these tests, namely, to ascertain whether treatment with the preservatives recommended for use on nets had any injurious action on their tensile strength when exposed to sunlight, either from the properties of the preservative or of such decomposition products as might arise in the course of weathering. 


\section{Exposure Tests.}

The fabrics were exposed on the flat roof of the Laboratory. This faces the sea and from it come the prevailing winds. Even with other winds the air is not polluted nearly as heavily as in industrial towns; accordingly the effect of acid fumes on the fibres may be considered as of little importance, especially as there is enough driven spray from the sea during storms to neutralize traces of acid.

The fabrics were exposed after being stretched by hand on wooden frames of the dimensions used for such tests at the National Physical Laboratory ; these permit of five two-inch strips, eight inches long, being cut both to test warp and weft, leaving a good margin from the edge so as to avoid any possible effects due to the wood. The frames were exposed horizontally.

The materials used were a thick cotton, sold in yard widths at almost three shillings a yard; a lighter cotton, same width, sold at twenty-two pence per yard, and a stout linen, same width, sold at twenty-eight pence per yard. The preservatives and their method of application are as previously given in the work on net preservation (1928). The results of the exposures are shown in the three tables. The tensile tests were carried out at the Royal William Yard, Plymouth, through the courtesy of the Superintendent and Mr. R. M. Filmer, F.I.C., Chief Chemist.

The tests were carried out upon strips 2 inches wide and $6 \frac{5}{8}$ inches between the grips of the Goodbrand Machine under the standard conditions for such tests. The columns show the percentage strength of the strips at breaking, the breaks being clean. The figures are the mean of the five determinations in each case and are calculated on the values for the untreated, unexposed, controls.

\section{TABLE I.}

To show deterioration in a heavy weight cotton fabric, initial tensile strength No. 1, warp 166, weft $276 \mathrm{lbs}$. per inch, No. 25, warp 165, weft $150 \mathrm{lbs}$. per inch, thickness approximately $0.8 \mathrm{~mm}$., exposed horizontally on the roof, Nos. 2-4, from 10/1/'25-10/1/'27, two years, Nos. 15-19, from 12/9/'25-18/11/'26, fourteen months, and Nos. 27-31, from 25/11/'26$25 / 3 / 29$, two years and four months. No. 25 is control for above from No. 15 onwards.

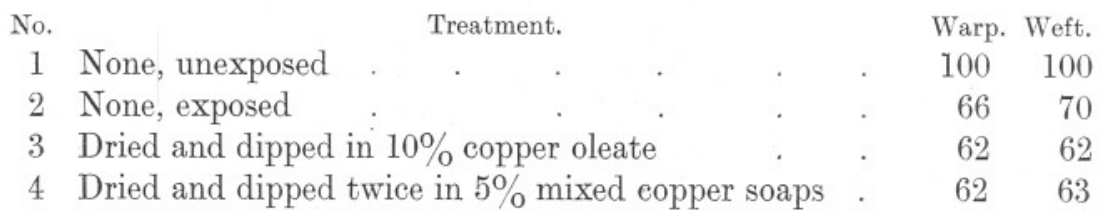


No.

15 None, exposed

Treatment.

Warp. Weft.

16 Dipped in 10\% mixed copper soaps . $\quad . \quad \begin{array}{lll}70 & 79\end{array}$

17 Do. $+\frac{1}{4}$ lb. resin per gallon . . . . $\quad 73 \quad 82$

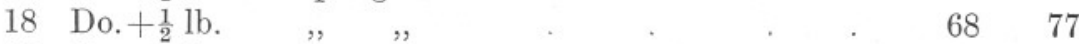

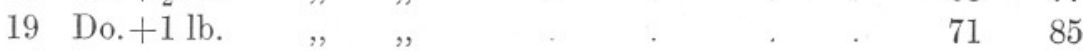

25 None, unexposed . . . . . . $\quad \begin{array}{llll}100 & 100\end{array}$

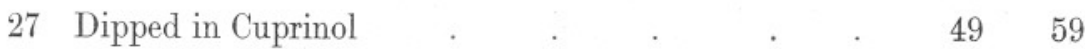

29 Dipped in $10 \%$ mixed copper soaps . . . $\quad \begin{array}{lll}62 & 75\end{array}$

30 Do. +2 oz. coal tar per gallon . . . . . $\quad \begin{array}{llll} & 65 & 65\end{array}$

31 Do.+4 oz. „, , , , . . . . . . . 64 . 70

TABLE II.

To show deterioration in a light weight cotton fabric, initial strength, warp 124, weft $78 \mathrm{lbs}$. per inch, approximately $0.5 \mathrm{~mm}$. thick, exposed horizontally on the roof from $10 / 1 / 25$ to $10 / 1 / 27$.

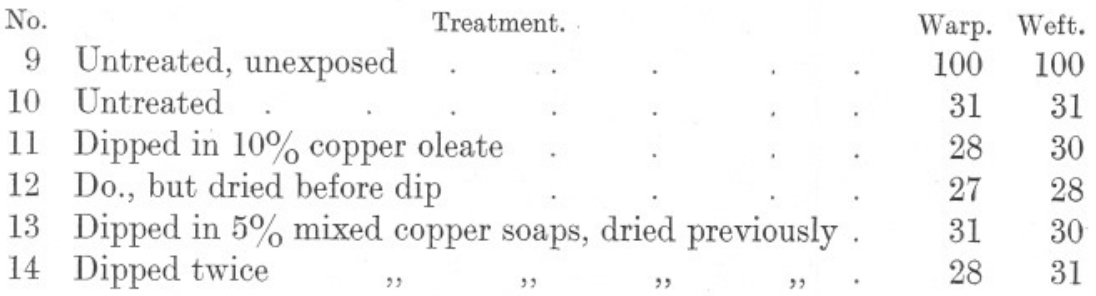

\section{TABLE III.}

To show deterioration in a heavy linen fabric, approximately $0 \cdot 7 \mathrm{~mm}$. thick, exposed horizontally on the roof, Nos. 6-8 for two years, 10/1/'25$10 / 1 / 27$, Nos. 20-24 from 12/9/'25-18/11/'26, viz. 14 months, Nos. 3236 , exposed $25 / 11 / 26-25 / 3 / 29$, two years and four months. No. 5 is control for Nos. 6-8 and had a tensile strength of $200 \mathrm{lbs}$. per inch in the warp and $178 \mathrm{lbs}$. in the weft. No. 26 is control for Nos. 20-24 and 32-36 ; it had a tensile strength of $170 \mathrm{lbs}$. per inch in the warp and $206 \mathrm{lbs}$ in the weft.

No.

Treatment.

Warp. Weft.

5 Untreated, unexposed . . . . . . 100100

6 Untreated . . . . . . . . $40 \quad 54$

7 Dipped in 10\% copper oleate ; previously dried $\quad \begin{array}{lll}39 & 57\end{array}$

8 Dipped in 5\% mixed copper soaps ; previously dried . $\quad 39 \quad 67$ 
Warp. Weft.

20 Untreated, exposed 12/9/25

55

$75 \quad 72$

21 Dipped in 10\% mixed copper soaps

22 Do. $+\frac{1}{4}$ lb. resin per gallon

23 Do. $+\frac{1}{2}$ lb. , , ,

24 Do. + l lb. ,, ,

26 Untreated, unexposed

32 Cuprinol, one dip, exposed 25/11/'26

35 Mixed copper soaps, one dip

36 Do. + tar 4 oz. per gallon, one dip
$70 \quad 85$

$69 \quad 83$

$76 \quad 79$

$100 \quad 100$

$42 \quad 65$

$60 \quad 68$

$54 \quad 66$

\section{DISCUSSION OF RESULTS.}

In the first series of exposures, Nos. 1-14, it may be seen that the cotton (Table I) lost about one-third of its strength in the two years, the thinner cotton (Table II) over two-thirds, and the linen (Table III) 60 per cent in warp and 46 per cent in weft. In all three sets the copper oleate or mixed copper soap (oleate, stearate, palmitate) treatment gave final strengths very close to that of the untreated fabrics. It is therefore obvious that the deterioration was due to the weathering, especially the action of light, since the copper soaps protect against bacteria and moulds. Under such conditions the effect of the latter appears to be negligible. The soaps, however, have not hastened the weathering action.

In the second series, Nos. 15-26, the treated cottons (Table I) are slightly weaker in the weft, but the same as or stronger than the control in the warp. The linen (Table III) is better than the control in both warp and weft, though the difference is not large. The resin copper soap mixtures adhere better and so resist the leaching action of rain, though after 14 months the upper surfaces showed no visible effects of the treatment, though the lower surfaces did.

The third series was again a two years' exposure, like the first. The copper soap treated cotton, No. 29, was very similar in its behaviour to that in the first set, No. 4, whereas the linen behaved rather better in the third series, ep. Nos. 35 and 7. The addition of tar to the soaps was intended to improve their adherence, which it does, and to cut off the light, which it does not appear to do, as far as the surface is concerned, for any length of time, for Nos. 30 and 31 are only slightly better than Nos. 3 and 4, these being cotton. With the linen, Nos. 35 and 36 , the preservation is rather better than in Nos. 7 and 8 . Very strangely the Cuprinol-treated fabrics, both linen and cotton, are appreciably weaker than the fatty soap and tar mixtures. Cuprinol, which is a copper soap of a 
petroleum acid, gives excellent protection against bacterial action and remains on the exposed fabric well, better than the fatty soaps alone.

None of the treatments tried, therefore, are really effective in lessening the destructive weathering action. Dr. R. H. Pickard, Director of the British Cotton Industry Research Association, kindly drew the author's attention to a method of preserving fabrics used at Woolwich, by means of precipitated chromium or chromium and iron hydroxides. The value of this treatment was made clear by work of Cunliffe and Farrow (1928), though they refer to Mr. J. R. Hannay for pointing out its value to them. It will be of interest to see whether it is not possible to combine this with the copper soap treatment. Possibly the chrome-green process alone may have an appreciable antiseptic action. In any case, it ought to be of value for sails and other fabrics exposed on a sea-going craft.

\section{SUMMARY.}

(1) Cotton and linen fabrics were exposed horizontally on the Laboratory roof at Plymouth for two years. During this time the fabrics lost from one to two-thirds of their initial tensile strengths in both warp and weft.

(2) The application of copper oleate, mixed copper soaps, also of the latter with resin or tar as binding agents, had no effect or a slight effect only in lessening deterioration; such weakening must therefore be due to weathering, chiefly the action of light, since these substances have been shown to be useful antiseptics on nets immersed in salt or fresh water.

(3) No deleterious action may be expected when nets treated with these substances are exposed to light, since the treated fabrics were no weaker than the untreated; but where Cuprinol had been used, there appears to have been some weakening, though the antiseptic properties of Cuprinol are excellent.

\section{REFERENCES.}

Atkins, W. R. G. 1928. The preservation of fishing nets by treatment with copper soaps and other substances. Journ. Mar. Biol. Assoc., 15, 219-235.

Cunliffe, P. W., And Farrow, F. D. 1928. The loss of strength (tendering) of cotton exposed to light. Shirley Inst. Mem., r, 1-20, No. 1. 
